\title{
Source apportionment of polycyclic aromatic hydrocarbons (PAHs) in sedi- ments from Khuzestan province, Iran
}

\author{
Josephine S. Lübeck", Kristoffer G. Poulsen",, Sofie B. Knudsen", Mohsen Soleimanib, Søren \\ Furbo , Giorgio Tomasi and Jan H. Christensen ${ }^{a, *}$
}

\author{
'Department of Plant \& Environmental Sciences, Section of Environmental Chemistry and - Physics, University of Copenha- \\ gen, Thorvaldsensvej DK-1871 Frederiksberg C, Denmark \\ ${ }^{\circ}$ Department of Natural Resources, Isfahan University of Technology, Isfahan, 84156-83111, Iran \\ ${ }^{*}$ Main authors \\ \# Corresponding author: jch@plen.ku.dk, 004535332456
}

\section{Abstract}

Khuzestan, Iran is heavily industrialised with petrochemical and refinery companies. Herein, sediment and soil samples were collected from Hendijan coast, Khore Mosa and Arvandroud River. The CHEMSIC (CHEmometric analysis of Selected Ion Chromatograms) method was used to assign the main sources of polycyclic aromatic hydrocarbons (PAHs) pollution. A four-component principal component analysis (PCA) model was obtained. While principal component 1 (PC1) was related to the total concentration of PAHs, the remaining PCs described three distinct sources: PC2 and PC3 collectively differentiate between weathered petrogenic and pyrogenic, and PC4 is indicative for a diagenetic input. The sources of PAHs in the Arvandroud River were mainly relatively fresh oil with some samples corresponding to a weathered oil input. Further, perylene (indicator for diagenetic source) was identified. Samples from Khore Mosa revealed a mixture with high proportions of highmolecular-weight PAHs, indicating a pyrogenic/weathered petrogenic source. Samples from Hendijan coast contained low relative concentrations of PAHs, thus only little information on pollution sources.

\section{Keywords}

Polycyclic aromatic hydrocarbons, chemical fingerprinting, CHEMSIC, Iran, principal component analysis 
The US Energy Information Administration (EIA) ranked Iran to hold the fourth-largest crude oil reserves which rounds up to $10 \%$ globally (US EIA, 2014). Thus, the risk of pollution due to production, refineries and transportation of oil is potentially high in this country. Approximately $80 \%$ of the Iranian onshore reserves are located in the Khuzestan province, in South-West Iran (Speight, 2015), which also comprises a protected wetland area, the Shadegan wildlife refuge. Wetlands are vulnerable to pollution originating either from petrochemical industries or agricultural activities. Hence, this area is likely contaminated with persistent petroleum hydrocarbons, pesticides and heavy metals, among others (Karimi et al., 2012, Davodi et al., 2011, Malekmohammadi and Blouchi, 2014, Dehghan Madiseh et al., 2009).

Petroleum hydrocarbons can be released to the environment via numerous paths, including oil spills and natural seeps (petrogenic sources), incomplete combustion of fossil fuels (pyrogenic) or transformation of non-hydrocarbon natural products (diagenetic) (UNEP/IOC/IAEA, 1992, Yunker et al., 2002). Relative compositions of thermodynamically stable and less stable polycyclic aromatic hydrocarbons (PAHs) can be utilised to identify hydrocarbon pollutant sources (Yunker et al., 2002, Christensen et al., 2005 and 2010, Wang et al., 2014). However, multiple sources and weathering processes (e.g. transformation due to photooxidation, biodegradation or evaporation) can hinder a correct identification and differentiation of sources (Readman et al., 2002).

Gas chromatography-mass spectrometry (GC-MS) is well suited for oil hydrocarbon fingerprinting due to a high peak capacity and selectivity for the analytes of interest providing the capability to distinguish between oil sources (Christensen et al., 2005, Wang et al., 2014, CEN/TR, 2011). Default methods often include peak integration of the GC-MS data to provide intensities (i.e. heights or areas) for each peak (Yunker et al., 2002, CEN/TR, 2011). However, manual inspection is generally required due to potential errors during automatic integration which makes the process labourintensive and time consuming.

The CHEMSIC method (CHEMometric analysis of sections of Selected Ion Chromatograms) is an alternative approach proposed by Christensen et al. (2005, 2007 and 2010) that makes use of unsupervised pattern recognition on pre-processed and combined selected ion chromatograms (SICS) for source identification and apportionment. CHEMSIC is based on the analysis of detector signals in a chromatogram ('pixel-based analysis') rather than on peak areas/heights or concentrations which leads to potentially less biased results (Christensen et al., 2005 and 2010). It introduces a tiered approach for data pre-processing in order to reduce instrumental artefacts such as retention time shifts, changes in peak shapes and detector sensitivity (Christensen and Tomasi, 2007). These artefacts can introduce variations unrelated to the chemical composition and thus might complicate the model interpretation as they will be partly modelled together with the chemical variation.

In this study, sediment samples from the Khuzestan province, Iran, around the Shadegan wetland (Figure 1) were analysed via GC-MS in selected ion monitoring (SIM) mode and by applying the CHEMSIC method. The objectives of this study were to describe hydrocarbon patterns for this area, to distinguish between pollution sources, and to identify weathered oil fingerprints as opposed to fingerprints of rather fresh oil spills. 


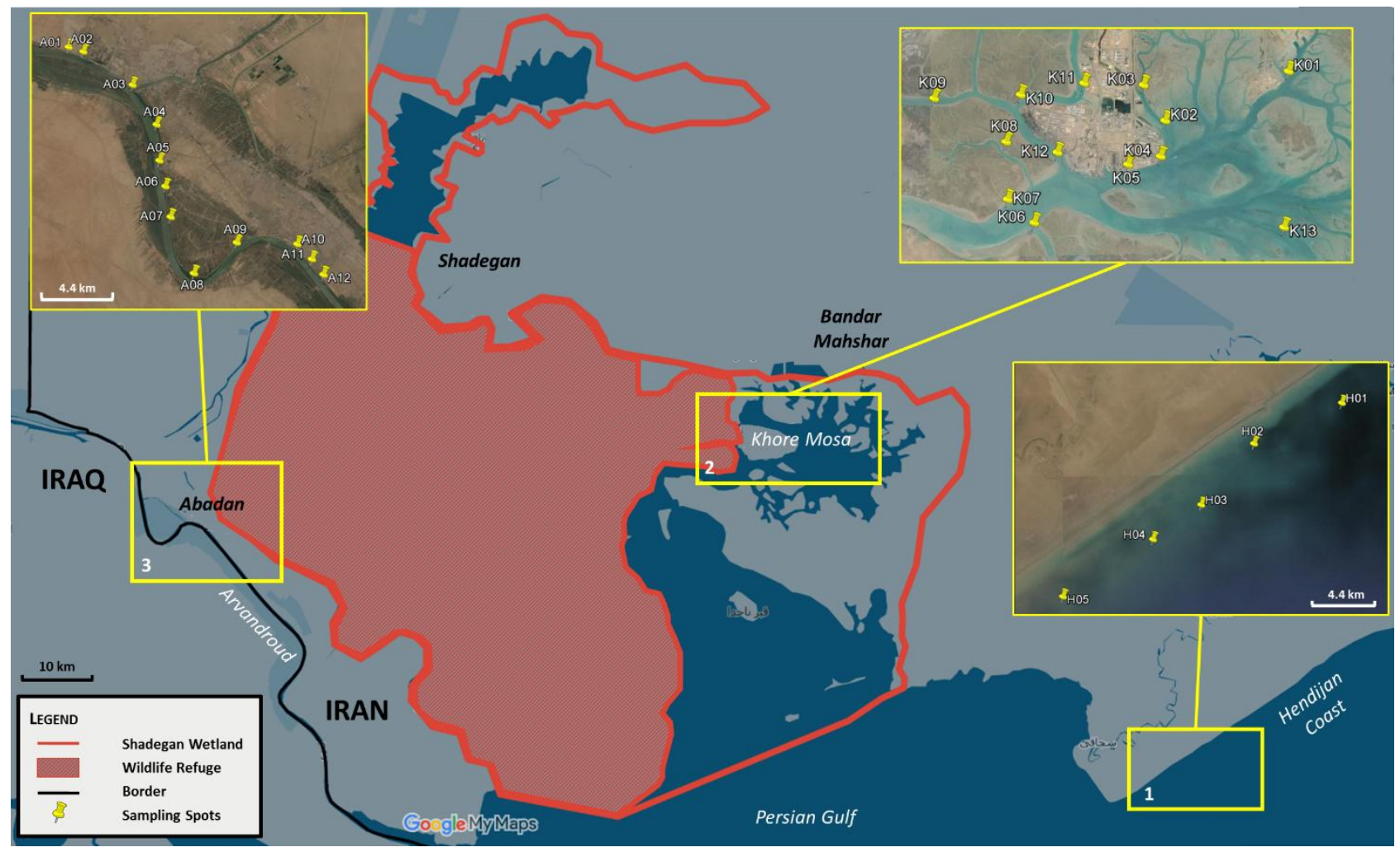

Figure 1: Sampling sites in Iran (1: Hendijan coast, 2: Khore Mosa, 3: Arvandroud). Note that at sampling site 1, three samples were taken at each of the given spots with a distance of $50 \mathrm{~m}$.

The Shadegan wetland covers a region of ca. 540.000 ha, and is comprised of freshwater, coastal and tidal zones (Figure 1). It is surrounded by cities such as Abadan, Bandar-Mahshahr and Shadegan (Malekmohammadi and Blouchi, 2014). The wetland was recognised as a vital ecosystem with a rich flora and fauna that is part of the subsistence of the surrounding villages and cities (CIWP, 2015). Almost $61 \%$ of the wetland area is protected as a Wildlife Refuge (EPA Iran and Rad, 2011). Abadan and Bandar-Mahshahr are densely populated industrial cities including large refinery/petrochemical industries, and harbours, e.g. "Bandar Imam Petrochemical Special Economic Zone" as one of the largest industrial zones in Iran (sampling zone 2, Figure 1). Petroleum products from Abadan refineries (e.g. Abadan Oil Refining Company with approximately 400.000 barrels of crude oil per day, NIORDC, 2015) are transported from the port of Bandar-Mahshahr. The largest marine port of Iran is located in the city of Imam Khomeini (sampling zone 2, Figure 1) and is directly connected to the Shadegan wetlands.

Samples were collected within three days in the end of October 2014 from three sampling zones in Khuzestan (Figure 1): In the coastal area of the Persian Gulf at the Hendijan Coast (1); close to the Shadegan wetland protected area near Khore Mosa creek, which extends from Mahshahr port in the North and the Persian Gulf in the South (2); and between Khorramshahr and Abadan at the border to Iraq on the Arvandroud River (3). At the Hendijan Coast, three samples were collected per sampling spot in a distance of approximately $50 \mathrm{~m}$ each. Hereafter, these samples were considered as sampling replicates $(n=15)$. In total, 47 sediment samples were collected with a Van Veen grab sampler from depths between 0.5 and $22.9 \mathrm{~m}$. 500-800 g of sediment were transferred to a flat stainless-steel metal bowl and homogenised before secondary sampling (in duplicates) and then transferred to polyamide bags $(30 \times 40 \mathrm{~cm}$, Rilsan, France). The samples were maintained at a maximum of $4^{\circ} \mathrm{C}$ until subsampling of $200 \mathrm{~g}$ into new polyamide bags. Samples were refrigerated $\left(4^{\circ} \mathrm{C}\right)$, transported to Copenhagen, Denmark and stored at $-20^{\circ} \mathrm{C}$ within $15 \mathrm{~h}$ after subsampling.

For the sample extraction, the following material was employed: dichloromethane (DCM), $n$-pentane, hydrochloric acid $(\mathrm{HCl}, 98 \%)$ and 2,2,4-trimethylpentane (isooctane) were all of HPLC grade (Rathburn, UK); silica gel 60 (0.063-0.200 mm, Merck, Germany) was activated for $15 \mathrm{~h}$ at $180^{\circ} \mathrm{C}$; fine 
copper powder ( $\geq 99 \%$ pro analysis, Fluka, USA) was activated with concentrated $\mathrm{HCl}$ and rinsed with deionised water and $n$-pentane. An internal standard (ISTD) mixture containing d8-naphthalene, d8dibenzothiophene, d10-acenaphthene, d10-phenanthrene, d10-pyrene, d10-fluorene, d12-chrysene, $\mathrm{d} 12$-benzo(k)fluoranthene, and $\mathrm{d} 12$-benzo(g,h,i)perylene, was added to the sediments prior to extraction, while a recovery standard (RSTD) mixture containing d10-anthracene, d12benz(a)anthracene, d12-benzo(a)pyrene, d12-ideno(1,2,3-c,d)pyrene was added to the final extract before the chemical analysis (Table 1. Pressurised liquid extraction was performed using an Accelerated Solvent Extractor (ASE-200 Dionex, USA) with $33 \mathrm{~mL}$ stainless-steel extraction cells. The method described by Soleimani et al. (2010) was used. Briefly, ASE cells were packed with two cellulose filters (GB-140, Advantec, MFS Inc., Japan) in the bottom and $4 \mathrm{~g}$ of activated silica gel on top. To remove elemental sulphur, $4 \mathrm{~g}$ of activated copper were added on top. The homogenised sediment sample $(5 \mathrm{~g})$ was thoroughly ground with an equal amount of activated hydromatrix $\left(450^{\circ} \mathrm{C}\right.$ for $15 \mathrm{~h}$, Sigma-Aldrich, USA), and subsequently and quantitatively added to the extraction cell. In order to correct for the loss of analytes during the extraction, $200 \mu \mathrm{L}$ of ISTD solution were added. The remaining cell volume was filled with heat-treated and chemically inert Ottawa sand (general purpose grade, Fisher Chemicals, Germany). A third cellulose filter was placed on top before capping the cell. Further, the cell was placed into the ASE and two extraction cycles were carried out. Blanks (two per extraction batch) were filled only with Ottawa sand instead of sample, but were treated in the same manner as the samples.

Approximately $25 \mathrm{~mL}$ were obtained from each extraction cycle, which were stored in two separate glass vials with n-pentane:DCM (90:10). The ASE parameters for each of the consecutive extractions were as follows: $1500 \mathrm{psi}, 100^{\circ} \mathrm{C}$, preheat $2 \mathrm{~min}$, static $5 \mathrm{~min}$, flush volume $70 \%$, purge time $60 \mathrm{~s}$. The two extracts were combined and concentrated to $8 \mathrm{~mL}$ with nitrogen gas in amber glass vials. Isooctane $(2 \mathrm{~mL}$ ) was added as a preservative and mixed gently, followed by evaporation to $2 \mathrm{~mL}$. The extract was then transferred to a $5 \mathrm{~mL}$ volumetric flask, $200 \mu \mathrm{L}$ of the RSTD mixture were added and n-pentane:DCM (90:10) was filled to the mark. The glass vials were rinsed three times with $n$ pentane:DCM (90:10) to ensure a full transfer.

The sediment extracts were analysed with an Agilent 6890N/5975 GC-MS operating in electron ionisation (EI) mode. The GC was equipped with a $60 \mathrm{~m}$ ZB-5 $(0.25 \mathrm{~mm}$ inner diameter, $0.25 \mu \mathrm{m}$ film thickness) capillary column (Phenomenex, USA). Helium was used as carrier gas with a flow rate of $1.1 \mathrm{~mL} \mathrm{~min}{ }^{-1}$. Aliquots of $1 \mu \mathrm{L}$ were injected in pulsed splitless mode with an inlet temperature of $315^{\circ} \mathrm{C}$. The column temperature programme was as follows: Initial temperature $40^{\circ} \mathrm{C}$ held for $2 \mathrm{~min}$, $25^{\circ} \mathrm{C} \mathrm{min}^{-1}$ to $100^{\circ} \mathrm{C}$ then followed by an increase of $5^{\circ} \mathrm{C} \mathrm{min}^{-1}$ to $315^{\circ} \mathrm{C}$ which was held for $13.4 \mathrm{~min}$ (total run time of $60.8 \mathrm{~min}$ ). The transfer line, ion source and quadrupole temperatures were $315^{\circ} \mathrm{C}, 230^{\circ} \mathrm{C}$ and $150^{\circ} \mathrm{C}$, respectively. A total of 55 mass-to-charge ratios $(\mathrm{m} / \mathrm{z})$ were acquired in SIM mode. The complete description of the GC-MS/SIM method can be found in Gallotta and Christensen (2012).

The extracts were divided randomly into four batches. The analytical sequence for each batch also

Table 1: List of compounds and corresponding SICs. (a Internal standards that were used for normalisation)

\begin{tabular}{|c|c|c|c|}
\hline Compounds & SIC & Deuterated Compounds ${ }^{a}$ & SIC \\
\hline $\begin{array}{l}\text { C2-Naphthalenes } \\
\text { C3-Naphthalenes }\end{array}$ & $\begin{array}{l}156 \\
170\end{array}$ & d8-Naphthalene & 136 \\
\hline $\begin{array}{l}\text { C0-Phenanthrene } \\
\text { C0-Anthracene } \\
\text { C4-Naphthalenes } \\
\text { C0-Dibenzothiophene } \\
\text { C1-Phenanthrenes } \\
\text { C1-Anthracenes }\end{array}$ & $\begin{array}{l}178 \\
184 \\
192\end{array}$ & $\begin{array}{l}\text { d10-Phenanthrene } \\
\text { d10-Anthracene }\end{array}$ & 188 \\
\hline C1-Dibenzothiophenes & 198 & d8-Dibenzothiophene & 192 \\
\hline $\begin{array}{l}\text { C0-Pyrene } \\
\text { C0-Fluoranthene } \\
\text { C1-Pyrene } \\
\text { C1-Fluoranthene }\end{array}$ & $\begin{array}{l}202 \\
216\end{array}$ & $\begin{array}{l}\text { d10-Pyrene } \\
\text { d10-Fluoranthene }\end{array}$ & 212 \\
\hline $\begin{array}{l}\text { C0-Chrysene } \\
\text { C0-Benz(a)anthracene } \\
\text { C1-Chrysene }\end{array}$ & $\begin{array}{l}228 \\
242\end{array}$ & $\begin{array}{l}\text { d12-Benz(a)anthracene } \\
\text { d12-Chrysene }\end{array}$ & 240 \\
\hline 5 Rings $\mathrm{PAHs}$ & 252 & $\begin{array}{l}\text { d12-Benzo(k)fluoranthene } \\
\text { d12-Benzo(a)pyrene }\end{array}$ & 264 \\
\hline 6 Rings PAHs & 276 & $\begin{array}{l}\text { d12-Benzo(ghi)-perylene } \\
\text { d12-Indeno(1,2,3-c,d)-pyrene }\end{array}$ & 288 \\
\hline
\end{tabular}


included several types of quality measures: Solvent blanks (n-pentane:DCM, 90:10), instrument test solutions and quality control (QC) samples were used to govern daily runs. Their chromatograms were inspected for cross-contamination, changes in peak shape, chromatographic resolution and sensitivity. The QC samples were mixtures of equal amounts of 15 randomly selected extracts from all three sampling sites. They were considered representative of the whole sample set and were also included in a test set used for validation during the subsequent chemometric data analysis. A total of 47 sample extracts including sampling replicates, eight QC samples and 12 extraction blanks were analysed. After preliminary evaluation, seven samples had to be removed due to contamination issues in the second sample extraction batch.

Using SICs instead of Total lon Chromatograms (TICS) facilitates modelling in PCA and source apportionment by including compounds of well-suited diagnostic ability and excluding compounds found in high concentrations but with low diagnostic ability (e.g. n-alkanes dominate the TIC presumably covering co-eluting compounds). As can be seen in Table 1, $12 \mathrm{SICs}$ of suitable diagnostic compounds (Gallotta and Christensen, 2012, de Fatima et al., 2007) and their appropriate ISTDs were chosen for the data analysis. For each SIC, the compounds of interest were identified by their retention times and $\mathrm{m} / \mathrm{z}$ according to the CEN/TR (2011) protocol. The SICs were cut to focus only on the peaks corresponding to the compounds of diagnostic relevance, and to remove sections with no chemical information (viz. trailing and leading sections). For the C2- and C3-naphthalenes (m/z 156 and 170) areas in-between relevant peaks had to be removed because ISTDs irrelevant to those ions (m/z $160 \mathrm{~d} 8$-acenaphthylene and m/z $176 \mathrm{~d} 10$-fluorene, respectively) also showed and interfered.

The chromatograms were exported in NetCDF format using ChemStation software (Agilent Technologies, USA), and processed and analysed in MATLAB 8.4.0 (R2014B, MathWork Inc., USA) using in-house developed scripts. Algorithms can be downloaded from www.models.life.ku.dk, e.g. iCDF to import CDF files, icoshift for retention time alignments, and Multiblock Toolbox v.0.2 for PCA modelling.

The dataset was split into a training set consisting of 30 samples, and a test set of eight QC samples and ten of the Hendijan Coast sampling replicates (two from each spot). The data was pre-processed accordingly to Christensen et al. $(2007,2010)$ in order to remove variations due to sampling, sample preparation and instrumental analysis (e.g. sensitivity of the detector) while maintaining chemical information. Thereby, reliable and reproducible results based only on the chemical composition can be obtained. First, baselines were removed by a Savitzky-Golay smoothing function, using the first order derivative, third order polynomial and a seven data point width (Savitzky and Golay, 1964). Second, samples were aligned using the icoshift algorithm (Tomasi et al., 2011). Each SIC was aligned individually to the corresponding SIC in a target sample, shifting the entire signal by insertion and deletion of SIC data endpoints. The target was chosen as the sample that gave the highest signals for most of the compounds of interest based on visual inspection of the raw data. The icoshift algorithm gave retention time shifts between 1 and 13 data points (equal to 0.356 to $4.626 \mathrm{~s}$ ). The relatively small shifts are a good indicator for a high quality of the chromatography, which is of utmost importance for the CHEMSIC method. Finally, each SIC was normalised to the absolute sum of the adjusted SIC containing only an appropriate ISTD (Table 1). Thus, focus was set on the total hydrocarbon concentration. Pre-processing was validated by projecting the test set on the PCA model, by visual inspection of loading and score plots, as well as by the chemical interpretation of the model coefficients.

The data was stacked in an $I \times J$ matrix $\mathbf{X}$, where $I$ denotes the number of samples and $J$ the total number of points of the combined SICs (i.e. $47 \times 3564$ data points). The matrix was modelled by PCA; thus, $\mathbf{X}$ was mean-centred column-wise and decomposed as $\mathbf{T P}^{\top}+\mathbf{E}$. The $I \times K$ score matrix $\mathbf{T}$ is column-wise orthogonal, the $J \times K$ loading matrix $\mathbf{P}$ is column-wise orthogonal with columns of unitary Euclidean norm. $\mathbf{E}$ denotes the matrix of residuals and $K$ is the number of principal components. 
Initially, 0 CO- and C1-naphthalenes were also selected for the identification of pollution input (viz. petrogenic, pyrogenic and diagenetic) and degree of weathering. However, they were excluded prior data analysis due to very low relative concentrations in all samples. This can be explained by preferential evaporation and dissolution of these low molecular-weight (MW) PAHs at the sampling sites or by the concentrating steps during sample preparation (CEN/TR, 2011). The 12 selected SICs range from $\mathrm{m} / \mathrm{z} 156$ to 276 covering the most important PAHs for the given aim of this study (see Table 1). Preliminary PCA models were calculated and components were evaluated. Sample A12 was identified as extreme due to high signals. The signal intensities of A12 were subsequently scaled down to $20 \%$ in order to reduce its influence on the model. New PCA models were calculated. In the principal components (PCS) past the fourth, chemical information was confounded with peak shape changes and residual shifts and were thus not analysed further (Christensen and Tomasi, 2007). Projecting the test set onto the model revealed low score variation amongst the QC samples and sampling replicates from both training and test set (Figure S1 and S2). In addition, low Q-residual scores indicate adequate data pre-processing (Figure S3).

Figure 2 shows the combined average chromatogram for the 30 samples. The average shows high signal intensities of C1-dibenzothiophenes, CO-phenanthrene and CO-pyrene; intermediate levels of C3-naphthalenes, $\mathrm{CO}$-anthracene, CO-fluoranthene, $\mathrm{C1}$-fluoranthenes and -pyrenes, $\mathrm{CO}$-chrysene and -benzo(a)anthracene, C1-chrysenes, and 5-ring PAHs; low levels of C2-naphthalenes, C4naphthalenes and CO-dibenzothiophene, C1-phenanthrenes and -anthracenes and 6-ring PAHs. This fingerprint of the average sample can be preceded as from a rather fresh petrogenic source, assuming that the normalised signal intensities reflect relative concentration levels.

The final four-component model explains $96.66 \%$ of the variation providing primarily quantitative information on the pollution levels for each sample relative to the average sample (i.e. in PC1). Components two to four focus more on the contributions from different sources of hydrocarbon

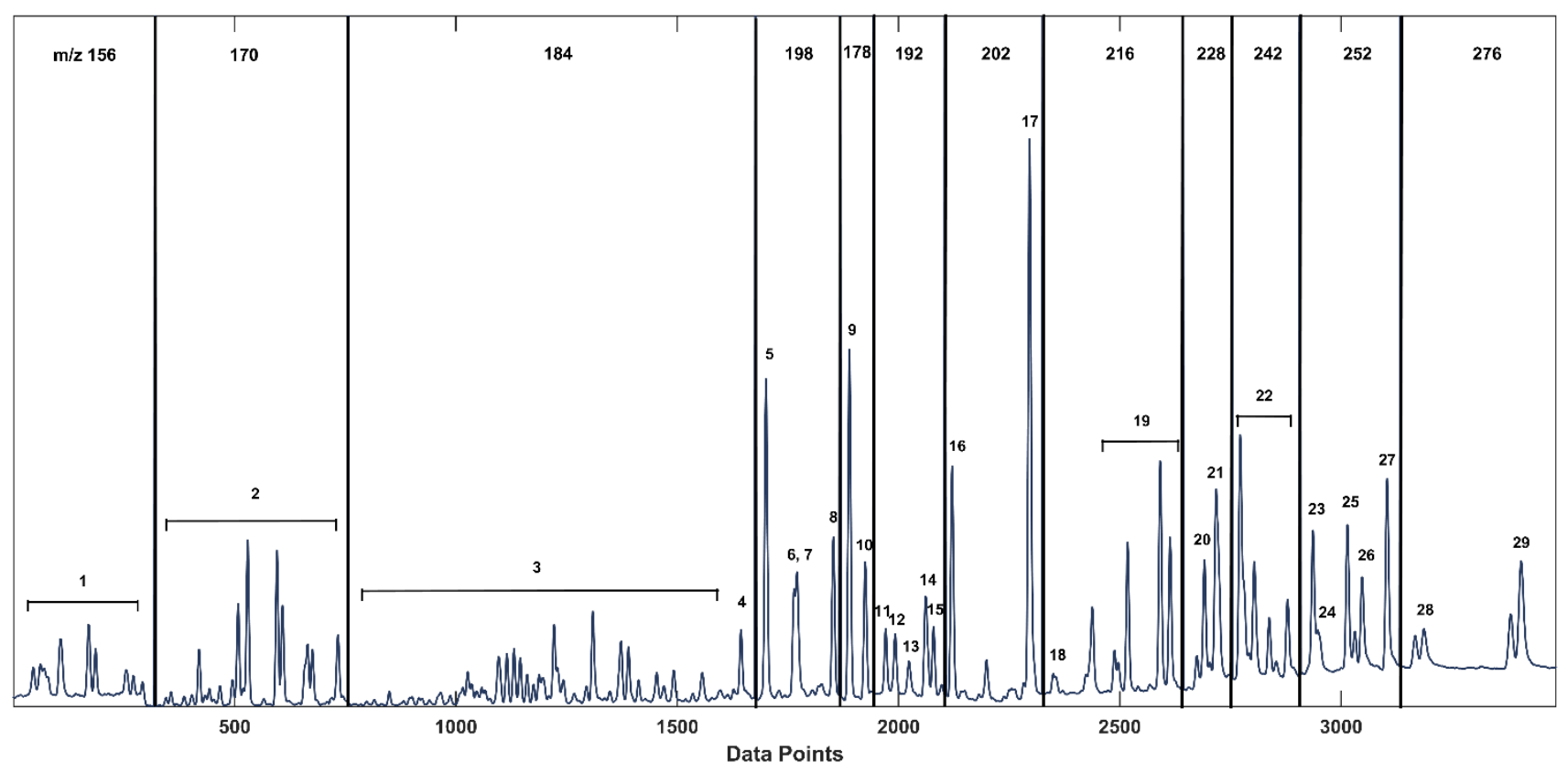

Figure 2: 12 relevant SICS (m/z 156-276) of the average combined SICS from 30 samples as the reduced dataset. The identities of peaks or peak clusters are: 1 - C2-Naphthalenes; 2 - C3-Naphthalenes; 3-C4-Naphthalenes; 4-CO-Dibenzothiophene; 5 - 4-Methyldibenzothiophene (4-MDT); 6-2-MDT; 7-3-MDT; 8-1-MDT; 9-Phenanthrene; 10 - Anthracene; 11 - 3-Methylphenanthrene (3-MP); 12 - 2-MP; 13 - Methylanthracene (MA); 14 - 4-MP/9-MP and MA (co-eluting); 15 - 1-MP; 16 - Fluoranthene; 17 - Pyrene; 18 - 2Methylfluoranthene; 19 -C1-Pyrenes; 20 - Benz(a)anthracene; 21 - Triphenylene/Chrysene (co-eluting); 22 - C1-Benzo(a)anthracenes/ Chrysenes; 23 - Benzo(b)fluoranthene; 24 - Benzo(k)fluoranthene; 25 - Benzo(e)pyrene; 26 - Benzo(a)pyrene; 27 - Perylene; 28 Indeno[1,2,3-c,d]pyrene; 29 -Benzo[g, h,i]perylene. 
pollution. Figure 3 resembles the loading plots of all four PCs. PC1 describes $58.55 \%$ of the variance, and has positive loading values for all SICS and compounds. A positive score in PC1 is in accordance with an above average pollution level whereas a negative score with a below average pollution level.

PC2 describes $58.55 \%$ of the variance. Minor positive PC2 loading coefficients are observed for low-MW C2- and C3-naphthalenes and C1dibenzothiophenes $(\mathrm{m} / \mathrm{z}$ 156, 170 and 198), while higher MW compounds (m/z 202, 216, 228, 242, 252 and 276) have negative PC2 loading coefficients (Figure 3). This PC describes the compositional variation with higher than average contributions from higher MW compounds $(\mathrm{m} / \mathrm{z}$ of 202 and above). This PC generates information on a mixture of a weathered petrogenic but also pyrogenic input. Especially the negative loading scores of C1pyrenes/-fluoranthenes and C1-chrysenes support that conclusion (Peters et al., 2007, Yunker et al., 2002). Large negative scores indicate samples with an

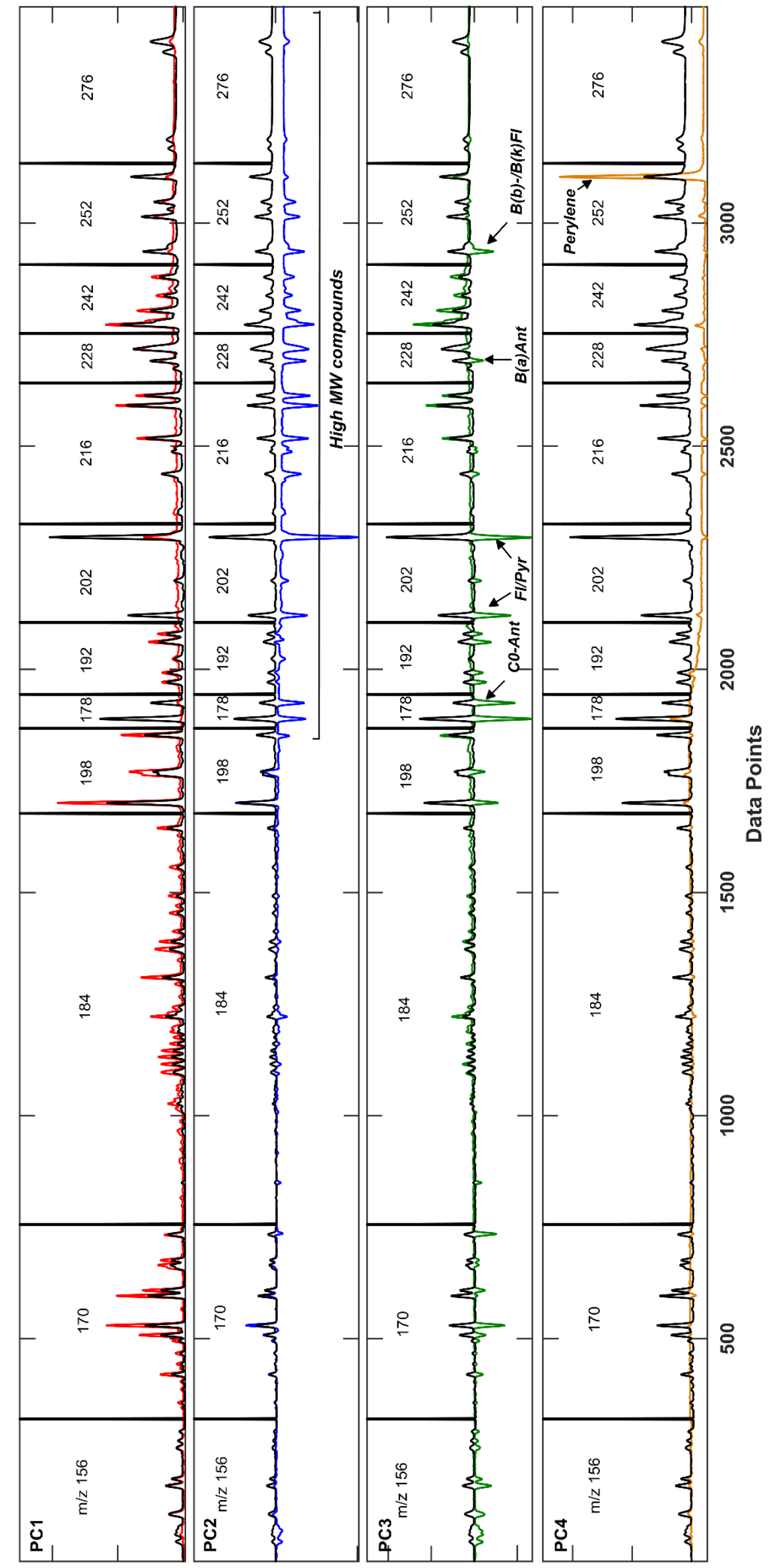

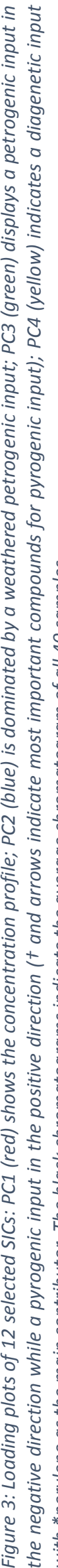


above average contribution from higher MW compounds.

PC3 (12.07\% of the variance) describes the source variation within the higher MW-compounds that have positive loading coefficients in PC2. The negative loading coefficients (PC3) of the non-alkylated species of anthracene, fluoranthene, pyrene and benzo(a)anthracene and benzo(b)-/ benzo(k)fluoranthene are indicative of pyrogenic sources (Peters et al., 2007), whereas positive loading coefficients for alkylated fluoranthenes and pyrenes, and for chrysenes (both alkylated and not) suggest a weathered petrogenic source (Peters et al., 2007). A large negative PC3 score suggests that the pollution is from a more pyrogenic source, while a large positive score indicates samples with larger contributions from a weathered petrogenic source.

PC4 describes only $2.29 \%$ of the variance, but still provides significant chemical information with a large positive loading coefficient for perylene ( $\mathrm{m} / \mathrm{z} 252)$, which is a known indicator of diagenetic input (Silliman et al., 2001). Thus, large positive PC4 scores indicate a diagenetic input.

Figure 4 illustrates a bar plot of all 30 samples, sorted by their score values on PC1 and categorised by sampling sites. The samples from the Hendijan Coast show very little variation. All these samples have below average concentration (according to PC1) and show no characteristic PAH source pattern of either petrogenic, pyrogenic or diagenetic input (PC2 to PC4). This was further confirmed by inspection of the raw data where all relevant SICS showed hardly any peaks compared to the blanks. The low level of PAHs in surface sediments is consistent with the low industrialisation of the area and the local ecology and climate. There are only a few old oil drilling wells in close proximity to the shore; any potential contribution from intact drilling platforms located further offshore or on open sea is likely to be quickly dissipated by local tidal conditions and currents.

Similar to the samples from the Hendijan Coast, samples K01 and K07 to K13 from the Khore Mosa area appear to have no significant levels of PAH contamination from any source. These samples were taken either outside of effluent zones of the different petrochemical plants (viz. samples K07, K12 and K13) or within the Shadegan Wildlife Refuge (samples K08 to K10).

Samples K02 to K04 have lower than average concentrations of PAHs (negative PC1 scores); their negative PC2 and PC3 scores suggest that the PAHs may have a mixed origin due to the presence of both pyrogenic- (i.e. non-alkylated anthracene, $\mathrm{m} / \mathrm{z}$ 178; fluoranthene and pyrene, $\mathrm{m} / \mathrm{z} 202$; benzo(a)anthracene, $\mathrm{m} / \mathrm{z} 228$; and benzo(b)-/benzo(k)fluoranthene, $\mathrm{m} / \mathrm{z} 252$ ) and petrogenic indicators (i.e. chrysene species at $\mathrm{m} / \mathrm{z} 228$ and 242, and alkylated pyrenes and fluoranthenes at $\mathrm{m} / \mathrm{z}$ 216). Differentiation between petrogenic, pyrogenic and diagenetic sources can be difficult since

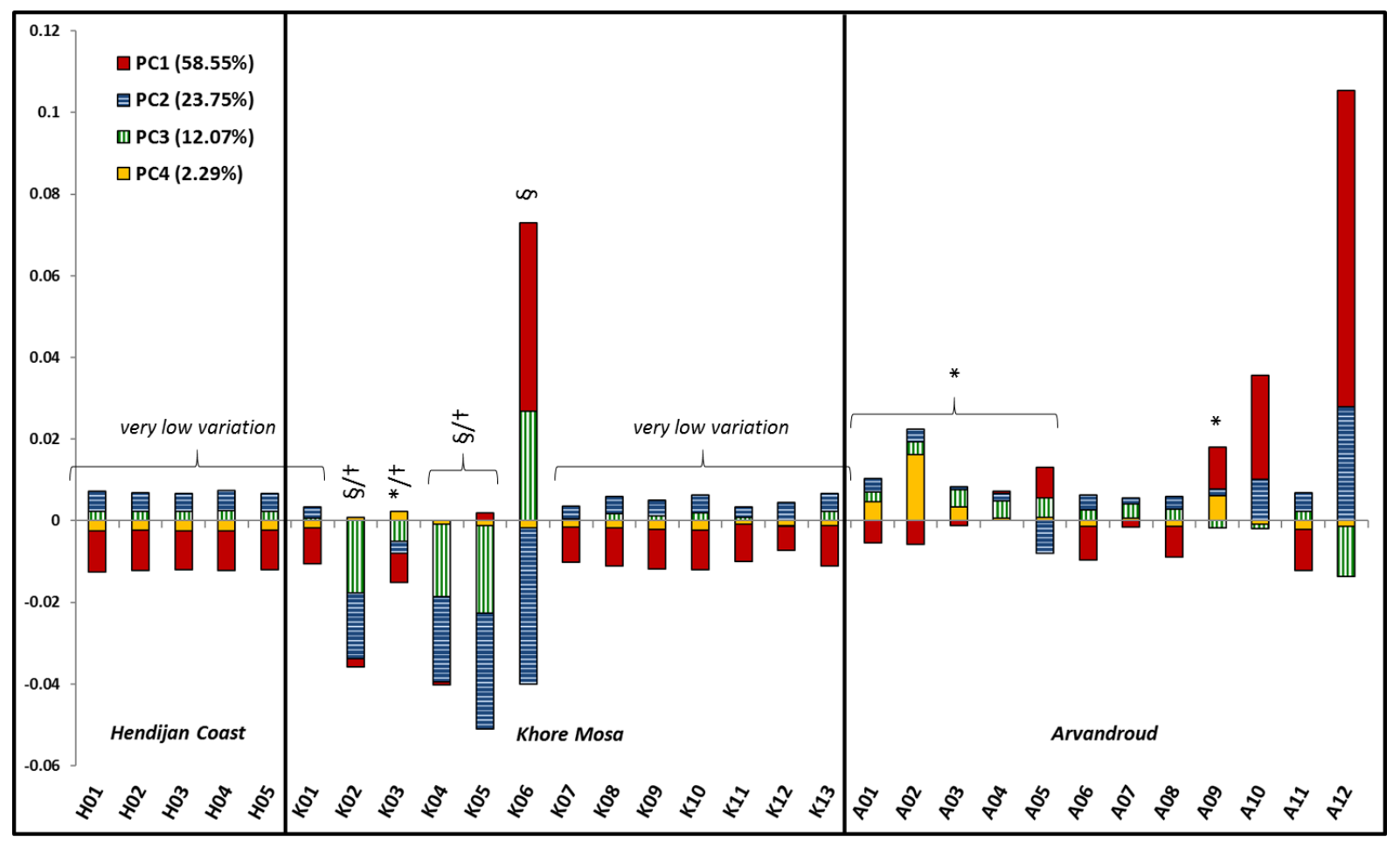

Figure 4: Bar plot with samples $(n=30)$ categorised by sampling sites. * - diagenetic input; + - pyrolytic input; $\S$ - petrogenic input. 
some of the PAHs can originate from more than one of the sources (Peters et al., 2007). Additionally, sample $\mathrm{KO3}$ has a contribution from PC4, therefore also a diagenetic input (perylene, $\mathrm{m} / \mathrm{z} 252$ ) (Tissot and Welte, 2012). Sample K05 revealed a very similar pattern as K04, however, with slightly above average contributions in PC1.

Sample K06 shows significant concentration levels of petrogenic origin with an above average level of contamination (positive PC1) and large negative and positive scores in PC2 and PC3, respectively. This indicates that the contamination is of a weathered petrogenic nature with large relative amounts of C1-fluoranthene, C1-pyrene and CO-/C1-chrysenes (m/z 216, 228 and 242). This sample was taken outside the effluent zones of the petrochemical plants and is contradictive with earlier results, i.e. samples $\mathrm{K06}$ and $\mathrm{K07}$ were taken in the same area of this waterway but show different patterns. An explanation could be an accidental petroleum contamination, since this waterway is used as an access point to the Bandar-Mahshahr port and an elevated naval traffic on a daily basis is given. Further, there might be some variation due to sampling in intertidal waters and sampling from varying depths, e.g. $\mathrm{KO} 6$ at $1.4 \mathrm{~m}$, and $\mathrm{KO}$ at $6.1 \mathrm{~m}$ ). Weathering processes as photooxidation, evaporation and biodegradation are more likely in surface waters followed by precipitation of higher MW PAHs onto the sediments.

Samples A06, A08 and A11 from the Arvandroud River appear to have no significant level of contamination from any source, similar to those samples from relatively pristine sites at Khore Mosa and the Hendijan Coast. Conversely, samples A01 to A03 have negative scores for PC1 and positive scores for PC2 to PC4, indicating low levels of PAH contamination, but largely dominating diagenetic inputs (Silliman et al., 2001). The diagenetic input appears smaller for samples A04 and A07 with smaller positive scores in PC4. Samples A01 to A04 were collected upstream of the Arvandroud River before the oil-processing plants and with a smaller input of petrogenic PAHs.

The contamination in sample $A 05$, while limited, seems to be of weathered petrogenic nature (negative PC2 and positive PC3). A small positive PC4 score also suggest some degree of diagenesis at this sampling spot. Sample A09 has the second largest diagenetic contribution and is the only diagenetic sample with an above average contamination level (positive PC1). A secondary higher MW anthropogenic input is suggested by a positive PC2, while an insignificant PC3 score provides no further distinction of weathered petrogenic or pyrogenic input.

Sample A10 displays the third largest relative contamination of all samples, and - together with positive scores for $\mathrm{PC2}$, and negative scores in $\mathrm{PC} 3$ and PC4 - suggests that the contamination is of a rather fresh/non-weathered petrogenic nature with relatively large amounts of C3- and C4naphthalenes and CO- and C1-dibenzothiophenes (Peters et al., 2007). Sample A12 is the most extreme of all samples with a very large positive PC1 score describing the largest relative concentration. This contamination was also identified as fresh/non-weathered petrogenic with relatively large amounts of lower MW PAHs. A positive PC2 score supports this observation and was confirmed further by inspection of the raw data. Samples A10 and A12 were collected respectively in front of and downstream from a local refinery, where a few oil slicks and continuous effluent input to the Arvandroud River were identified.

In order to support the results from the PCA analysis, total petroleum hydrocarbon (TPH) concentrations of all samples were determined via GC-flame ionisation detection (FID). The results and analytical method were described and attached in the supporting information (Table S1). Generally, TPH concentrations were low or below the limit of detection (LOD), which can be explained by the tropical climate conditions, sandy sediments and rather low organic matter content (1.46 to 8.97\%, determined experimentally according to ASTM D2974). These are factors promoting degradation and lower sorption (Neff, 2002). High TPH concentrations were observed for K06, A05, A09, A10 and A12 which fits well with the observations from PC1 in the PCA analysis. Some other samples revealed elevated TPH concentrations which were not seen in PC1. Considering that TPH determination is taking into account all hydrocarbons from C10 to C35, which includes n-alkanes, cycloalkanes, PAHs, etc., this is still reasonable. 
In conclusion, it was possible to separate the sampling sites according to the level of contamination, and to discriminate the main sources of PAHs although partly confounded with a degree of weathering. The samples from the Hendijan Coast contained very low hydrocarbon input. Samples with highest relative concentration of fresh petroleum were found in the Arvandroud River where oil-producing refineries are located. Most of the samples in Khore Mosa showed a weathered petrogenic or pyrogenic PAH pattern, which could be linked to petrochemical industries using and burning petroleum fuel. Some samples in the Arvandroud River demonstrated a clear diagenetic source input of PAHs. However, many samples were of mixed origin and it was not possible to determine specific sources.

\section{Acknowledgement}

The authors would like to thank the Danish Chemistry Society, KU Jubilaeumsfondet, Statsautoriseret revisor Oluf Christian Olsen og hustru Julie Rasmine Olsens Mindefond, Sigurd Torvborg Jenses legat, Fonden til st $\varnothing$ tte for studerende inden for fødevareviden-skab og naturressourcer på SCIENCE and Julie Damms Studiefond for the financial support. Further, we want to acknowledge the Environmental Protection Agencies in Khuzestan, Abadan, Khorramshahr and Mahshahr, and Ahmadreza Lahijanzadeh (DOE Director General of Khuzestan Province), Mohammad Sadeghsaba and Ali Mokhtar Pour (OPCR Officer from Marine Environmental Protection Senior) for the immense support on site in Iran. We would like to thank the experts in laboratories and data analysis of the Research Centre for Advanced Analytical Chemistry, Jette Petersen and Peter Christensen; and at the Science and Technology Park in Isfahan, Iran for valuable assistance in sample preparation and data investigation.

\section{References}

CEN/TR European Committee for Standardization, 2011. Oil spill identification - Waterborne petroleum and petroleum products - Part 2: Analytical methodology and interpretation of results based on GC-FID and GC-MS low resolution analyses. CEN/TR 15522-2:2011.

Christensen, J.H., Hansen, A.B., Karlson, U., Mortensen, J. \& Andersen, O., 2005. Multivariate statistical methods for evaluating biodegradation of mineral oil. Journal of Chromatography A 1090 (1-2), 133-145.

Christensen, J.H. \& Tomasi, G., 2007. Practical aspects of chemometrics for oil spill fingerprinting. Journal of Chromatography A 1169 (1-2), 1-22.

Christensen, J.H., Tomasi, G., De Lemos Scofield, A. \& De Fatima Guadalupe Meniconi, M., 2010. A novel approach for characterization of polycyclic aromatic hydrocarbon (PAH) pollution patterns in sediments from Guanabara Bay, Rio de Janeiro, Brazil. Environmental Pollution 158 (10), 3290-3297.

Davodi, M., Esmaili-Sari, A. \& Bahramifarr, N., 2011. Concentration of polychlorinated biphenyls and organochlorine pesticides in some edible fish species from the Shadegan Marshes (Iran). Ecotoxicology Environmental Safety 74 (3), 294-300.

De Fatima, M., Meniconi, G. \& Barbanti, S.M., 2007. 17 - Case study: Evaluation of hydrocarbon sources in Guanabara Bay, Brazil. In Oil Spill Environmental Forensics. Burlington: Academic Press, 505-536.

Dehghan Madiseh, S., Savary, A., Parham, H. \& Sabzalizadeh, S., 2009. Determination of the level of contamination in Khuzestan coastal waters (Northern Persian Gulf) by using an ecological risk index. Environmental Monitoring Assessment 159 (1-4), 521-530.

EPA (Environmental Protection Agency) Iran, \& Rad, H.M., 2011. Shadegan Wetland integrated management plan [Online]. UNDP/GEF Conservation of Iranian Wetlands in collaboration Governmental organizations NGOs and Local Communities of Shadegan Wetland. Available: http://www.ramsar.org/sites/default/files/documents/library/shadeganmanagementplani.r._iran2011.pdf [Accessed 15.02. 2015]. 
Gallotta, F.D. \& Christensen, J.H., 2012. Source identification of petroleum hydrocarbons in soil and sediments from Iguacu River Watershed, Parana, Brazil using the CHEMSIC method (CHEMometric analysis of Selected Ion Chromatograms). Journal of Chromatography A 1235, 149-58.

Horel, A., Mortazavi, B. \& Sobecky, P.A., 2015. Input of organic matter enhances degradation of weathered diesel fuel in sub-tropical sediments. Science of the Total Environment 533, 8290.

Karimi, F., Moattar, F., Farshchi, P., Savari, A. \& Parham, H., 2012. Ecological Risk Assessment of Agricultural Pesticides throughout the Shadegan Wetland, Iran. Journal of Agricultural Science 4 (5).

Malekmohammadi, B. \& Blouchi, L.R., 2014. Ecological risk assessment of wetland ecosystems using Multi Criteria Decision Making and Geographic Information System. Ecological Indicators 41, 133-144.

Neff, J.M., 2002. Chapter 15 - Polycyclic Aromatic Hydrocarbons in the Ocean. In: Bioaccumulation in Marine Organisms: Effect of Contaminants from Oil Well Produced Water. Elsevier Science, 241-318.

NIORDC - National Iranian OIL Refining \& Distribution Company, 2015. Abadan Oil Refining Company Available: http://www.niordc.ir/index.aspx?fkeyid=\&siteid=77\&pageid=363 [Accessed 13.02. 2015].

Peters, K.E., Walters, C.C. \& Moldowan, J.M., 2007. The Biomarker Guide: Volume 2, Biomarkers and Isotopes in Petroleum Systems and Earth History. Cambridge University Press.

CIWP - Conservation of Iranian Wetlands Project. 2015. About Conservation of Iranian Wetlands Project [Online]. Available: http://wetlandsproject.ir/English/Default.aspx [Accessed 13.02. 2015].

Readman, J.W., Fillmann, G., Tolosa, I., Bartocci, J., Villeneuve, J.P., Catinni, C. \& Mee, L.D., 2002. Petroleum and PAH contamination of the Black Sea. Marine Pollution Bullettin 44 (1), 48-62.

Savitzky, A. \& Golay, M.J.E., 1964. Smoothing + Differentiation of Data by Simplified Least Squares Procedures. Analytical Chemistry 36 (8), 1627-1639.

Silliman, J.E., Meyers, P.A., Eadie, B.J. \& Klump, J.V., 2001. A hypothesis for the origin of perylene based on its low abundance in sediments of Green Bay, Wisconsin. Chemical Geology 177 (34), 309-322.

Soleimani, M., Afyuni, M., Hajabbasi, M.A., Nourbakhsh, F., Sabzalian, M.R. \& Christensen, J.H., 2010. Phytoremediation of an aged petroleum contaminated soil using endophyte infected and non-infected grasses. Chemosphere 81 (9), 1084-1090.

Speight, J.G., 2015. Chapter 1 - Occurrence and Formation of Crude Oil and Natural Gas. In: Subsea and Deepwater Oil and Gas Science Technology, 1-43.

Tissot, B. \& Welte, D., 2012. Petroleum Formation and Occurrence: A New Approach to Oil and Gas Exploration, Springer, Berlin Heidelberg.

Tomasi, G., Savorani, F. \& Engelsen, S.B., 2011. icoshift: An effective tool for the alignment of chromatographic data. Journal of Chromatography A 1218 (43), 7832-7840.

UNEP/IOC/IAEA, 1992. Determination of petroleum hydrocarbons in sediments, Reference Methods for Marine pollution Studies No. 20.

US EIA - Energy Information Administration, 2014. Iran, Independent Statistics \& Analysis [Online]. EIA. $\quad$ Available: http://www.eia.gov/beta/international/analysis_includes/countries_long//ran/iran.pdf [Accessed 16.02. 2015].

Wang, Z., Yang, C., Parrott, J.L., Frank, R.A., Yang, Z., Brown, C.E., Hollebone, B.P., Landriault, M., Fieldhouse, B., Liu, Y., Zhang, G. \& Hewitt, L.M., 2014. Forensic source differentiation of 
petrogenic, pyrogenic, and biogenic hydrocarbons in Canadian oil sands environmental samples. Journal of Hazardous Materials 271, 166-177.

Yunker, M.B., Macdonald, R.W., Vingarzan, R., Mitchell, R.H., Goyette, D. \& Sylvestre, S., 2002. PAHs in the Fraser River basin: a critical appraisal of PAH ratios as indicators of PAH source and composition. Organic Geochemistry 33 (4), 489-515. 